\title{
The Impact of the Handling Unit on Logistics Costs: The Case of a Portuguese Food Retail Supply Chain
}

\author{
Ana Luísa Ferreira Andrade Ramos \\ GOVCOPP/DEGEIT, University of Aveiro, \\ Campo de Santiago, 3810-193 Aveiro, Portugal. \\ Corresponding author: aramos@ua.pt
José António Vasconcelos Ferreira GOVCOPP/DEGEIT, University of Aveiro, E-mail: josev@ua.pt \\ Campo de Santiago, 3810-193 Aveiro, Portugal. \\ Sara Rego da Costa \\ DEGEIT, University of Aveiro, \\ Campo de Santiago, 3810-193 Aveiro, Portugal. \\ E-mail: sararego@ua.pt
}

(Received March 14, 2020; Accepted May 25, 2020)

\begin{abstract}
In the food retail industry, the agility and responsiveness of the supply chain are crucial because demand is volatile and short lead times are mandatory. The logistics performance is of critical importance to provide a high level of efficiency in operations and a high degree of customer satisfaction. The Handling Unit, or the minimum quantity to send to retail stores (the ship-pack), is a factor of considerable influence on logistics efficiency and costs. In this work, it was developed a simple analytical cost model for a Portuguese food retail two-tier distribution system (distribution centre and store) to support the evaluation of the conversion of the handling unit to half-pallet. The results of the model, considering a pilot study with three scenarios, suggest an economic gain of approximately $75 \%$ (comparatively to the current situation) in logistics costs. These quantitative results were decisive to guide decision-makers.
\end{abstract}

Keywords- Decision-support, Food retail sector, Handling unit, Warehouse environment, Two-tier distribution system.

\section{Introduction}

Operations managers work on large-scale, complex, socio-technical systems based on customized services and delivery of value to society, engaged in a circular economy pushing the frontiers of environmental sustainability (Nasir et al., 2017). Their fundamental activity is to decide on the utilization of the available resources, at the lowest cost, to satisfy the different stakeholders (business partners, clients, workers, suppliers, etc.). Decisions have trade-offs therefore decisionsupport tools are highly valued and, in an industrial engineering context, these tools rely, basically, on models.

In the food retail industry, the demand is highly volatile and lead times are progressively shorter so, the related supply chains need to be very agile and able to accommodate deviations "in the last minute". The agility principle means to produce according to varying customer needs (Tarafdar and Qrunfleh, 2017). The management of the supply chain or Supply Chain Management (SCM) is a critical task being the most popular operations strategy for improving organizational competitiveness in the twenty-first century (Gunasekaran and Ngai, 2005). The supply chain 
strategies play an important role in linking the high-level strategy of the organization with its activities (Perez-Franco et al., 2016) such as procurement, production planning and scheduling, inventory control, logistics and distribution.

Logistics plays a fundamental role in supporting retail companies to rationalize their distribution infrastructure and to make more efficient use of their resources (Bourlakis and Bourlakis, 2001). However, over the last years, it is taking place a major transformation in retail logistics, driven by changes in demand and stimulated by new technologies such as e-commerce, mobile commerce, tracking and tracing, and data analytics and these new retail business models are creating new dynamics and challenges that need to be addressed and studied (Mena and Bourlakis, 2016).

The Handling Unit (HU), or the minimum quantity to send to retail stores (the ship-pack), is a factor of considerable influence on logistics efficiency and costs. The HU can have a significant impact on productivity and ergonomics as well as on sales volume and service level. These aspects are critical on modern supply chains so, models to support decisions in the retail industry, and in particular, to help select the "best handling unit" in the supply chain, are needed and play a very important role in the daily operations of these supply chains. The main models involved in these operations are quantitative or mathematical models that allow gaining insight into complex systems providing numerical answers to impel continuous improvement. Decision-support-type models are critical to helping industrial (and service) managers in achieving their goals (Chiu et al., 2020).

In this work, it was developed an analytical cost model for a Portuguese food retail two-tier distribution system (distribution centre and store) to support the evaluation of the conversion of the handling unit to half-pallet. The model involves several cost components divided into three main categories: handling costs at the distribution centre, handling costs at the store, and inventory costs at both locations. The results of the model, for a given pilot study, suggest an economic gain of approximately $75 \%$ (comparatively to the current situation) in logistics costs. These quantitative results were decisive to provide guidance to decision-makers.

Case research and field-based studies are one of the most powerful research methods in operations management (Voss et al., 2002). As a research-based on a case study, this work explores a presentday phenomenon within its real-life context and the main objective is to create evidence on the importance of choosing the adequate handling unit to support the operations in the supply chain. Furthermore, the work highlights the critical role of quantitative models to support decisions and the daily system's operation.

The remainder of the paper is organized as follows. Section 2 provides a literature background for the main topics discussed in this work. In Section 3, the case study is presented. In Section 4 the key results and findings are discussed. Finally, Section 5 presents the main conclusions and directions for future research.

\section{Literature Background}

This section presents the main works published in recent years regarding the operations in the food retail industry and, in particular, the challenges related to the handling unit at the distribution centres.

\subsection{Food Retail Supply Chain and Distribution Centres' Dynamics}

Food supply chains are one of the most critical supply chains of our world (Das, 2019) and their 
International Journal of Mathematical, Engineering and Management Sciences

Vol. 5, No. 5, 835-850, 2020

https://doi.org/10.33889/IJMEMS.2020.5.5.065

competitiveness relies on its performance management and the integration of the different partners (Forslund, 2015; Prajogo et al., 2016). In the food retail industry, logistics performance is of critical importance to provide a high level of efficiency in operations and a high degree of customer satisfaction. This performance is reflected on key performance indicators such as the availability of the product on the shelf (OSA: On-Shelf Availability) and mirrors the decisions taken along the supply chain such as operations management at the different logistics' subsystems (Holweg et al., 2016), stock management, selection of products/product mix to exhibit on the shelf (Eroglu et al., 2011), shelf space allocated to each product (Corsten and Gruen, 2003). The service level and due dates are also key factors for retail companies' sustainability (Forslund, 2015).

In this context, the determination of packaging quantities and formats, to move along the supply chain, is a theme of particular interest having a great impact on logistics' costs and consumers' demand and loyalty (Albán et al., 2015; Sternbeck, 2015). The retail companies are not, any longer, passive recipients of products but, instead, they control the product supply in reaction to customer demand and "they control, organize and manage the supply chain from production to consumption" (Fernie et al., 2010).

Kuhn and Sternbeck (2013) divide the retail supply chain into three logistics subsystems namely, distribution centre, transport (to the store, or outbound transportation) and retail store. This work focuses on the operations at the distribution centre so, in this chapter, this subsystem will be highlighted.

The retail store is the "front-end" subsystem where the OSA indicator reflects the service level and the customers' satisfaction. Along with OSA, factors such as product variety, employees' attitude and availability, and overall store atmosphere also contribute to customer loyalty (Molina et al., 2009; Kuhn and Sternbeck, 2013). The efficient alliance between logistics and marketing is highly visible "at the shelf" in the store. The marketing function estimates consumers' demand and the logistics function satisfies that demand minimizing the supply chain costs. These costs include, mainly, transportation costs, inventory carrying costs (acquisition, order processing, capital, warehousing and handling, losses or rupture), and logistics administration costs (Schramm-Klein and Morschett, 2006).

The distribution centre (or a warehouse where distribution is the main function) has a key role in the retail supply chain due to the reduced size of buffers in stores. Therefore, the distribution centre has several main functions such as (1) to buffer the flow of materials along the supply chain to react to variable demand, (2) to consolidate products from various suppliers for combined delivery to customers, (3) to add value to products with operations such as kitting or labelling, (4) to take advantage of quantity discounts, and (5) to provide a buffer location for trans-shipments (de Koster et al., 2007; Gu et al., 2007).

The basic processes or operations taking place at the typical distribution centre can be classified into five main categories (de Koster et al., 2007): receiving, transfer and storage the Stock Keeping Units (SKUs) (with or without repackaging), order picking/selection, accumulation/sortation (pack and stack on the customer unit load), cross-docking and shipping. The widespread utilization of new information technologies such as RFID, GPS, and AS/RS offers new opportunities and challenges in the warehouse (design and) operations.

The main problems/decisions reported in the literature concerning warehouse operations are the 
International Journal of Mathematical, Engineering and Management Sciences

Vol. 5, No. 5, 835-850, 2020

https://doi.org/10.33889/IJMEMS.2020.5.5.065

following (Gu et al., 2007): truck-dock assignment, assignment of SKUs and space allocation, batch size, assignment of pickers, routing and sequencing of order picking tours, dwell point selection (for AS/RS) and order-lane assignment.

These are some operational challenges at modern warehousing systems, which need to be tackled in an integrated and dynamic way. According to $\mathrm{Gu}$ et al. (2007), given the prevalence of warehouses in the supply chains, research results on warehouse operational modelling can have a significant economic impact.

\subsection{Handling Unit}

The Handling Unit (HU) at the distribution centre is a key concern and a factor of considerable influence on logistics efficiency and costs. According to Wen et al. (2012), the HU or ship-pack is the unit sent to the store and can typically be placed on a shelf as an "each" or individual unit, an "inner" (a packaged set of "eaches", of about 68 units), or a case (e.g., a box of 24 units).

At the distribution centre, the HU is the minimum quantity to send to retail stores and has a great impact on picking operations. According to de Koster et al. (2007), picking operations represent more than $50 \%$ of operational costs at distribution centres. Wen et al. (2012) state that the warehouse has a greater handling cost when it replenishes with eaches or inners because the warehouse needs to spend some time cutting open cases to replenish the picking area for either inners or eaches and each replenishment order from the store entails more picking operations. However, replenishing with cases can impel the centre to carry more safety stock due to larger demand variability. At the store, using cases may increase inventory (multiples of case quantity) requiring a backroom or a high-level shelf to store the additional stock.

Besides the impact on the different logistics subsystems, the HU has also a considerable impact on logistic processes such as out-of-stock management, inventory control, shelf space management, and assortment planning.

The dimension of the HU can be one of the causes for stock out (Avlijas et al., 2015). The inefficient operations at the store can origin an absence of product in-store or absence of product on a shelf. The product availability represents a trade-off between inventory costs and handling costs. The shelf is the key resource of the retail supply chain and the related space is very scarce due to the intense competition between products and brands. The shelf space should be dimensioned according to the handling unit sent by the distribution centre to avoid backroom storage and this handling unit should highlight the product visibility at the shelf influencing the consumer (Hübner and Schaal, 2017). The assortment planning is, obviously, an important question because the variety of products on the shelf influences the consumer and this variety is dictated by the HU and the space allocated on the shelf. According to Broekmeulen et al. (2017), the stock at backroom space and the frequency of product replenishment depend on store characteristics, such as SKU demand and the allocated shelf space for the SKU, but also the type of replenishment policy.

As the majority of operations management problems, the challenge of finding adequate $\mathrm{HU}$ for the supply chain demands a quantitative modelling approach. Quantitative or mathematical models provide numerical answers and can be of type: analytic (based on a set of equations that can be solved to find a set of solutions), simulation (used when the analytical methods are not realistic and there is a need to test complex operational scenarios), or judgemental (provide representations based on opinions of experts, which are particularly useful when there is lack of information). At a 
International Journal of Mathematical, Engineering and Management Sciences

Vol. 5, No. 5, 835-850, 2020

https://doi.org/10.33889/IJMEMS.2020.5.5.065

lower level, they can also be classified into deterministic/stochastic, discrete/continuous, and static/dynamic.

The models available in the literature concerning the sizing of the handling unit are relatively scarce being the bulk research related to inventory management and shelf stacking operations. Table 1 depicts a synthesis of the central studies published during the last years concerning the logistics costs considered in analytical cost models to compute the most suitable handling unit in the retail supply chain.

Table 1. Logistics cost components used in the models for dimensioning the HU

\begin{tabular}{|c|c|c|c|c|c|}
\hline \multirow[t]{2}{*}{ Logistics subsystem } & \multirow[t]{2}{*}{ Cost component } & \multicolumn{4}{|c|}{ Studies/Authors } \\
\hline & & $\begin{array}{c}\text { Wen et al. } \\
\text { (2012) }\end{array}$ & $\begin{array}{c}\text { Sternbeck and } \\
\text { Kuhn (2014) }\end{array}$ & $\begin{array}{c}\text { Sternbeck } \\
(2015)\end{array}$ & $\begin{array}{l}\text { Broekmeulen et } \\
\text { al. (2017) }\end{array}$ \\
\hline \multirow[t]{5}{*}{ Distribution centre } & Holding & - & & & \\
\hline & Picking & - & - & & - \\
\hline & Replenishment & - & & & \\
\hline & Order & - & & & \\
\hline & Unpacking & & & & - \\
\hline Transport & Transportation & & - & & \\
\hline \multirow[t]{8}{*}{ Retail store } & Inventory (Capital) & - & - & - & - \\
\hline & Backroom store & & & & - \\
\hline & Shelf stacking & - & - & - & - \\
\hline & Shelf refilling & - & - & - & - \\
\hline & Reception & - & - & & \\
\hline & Rupture & & & & - \\
\hline & Unpacking & & & & - \\
\hline & Order & & - & & \\
\hline
\end{tabular}

Wen et al. (2012) discuss the optimum quantity for the ship-pack in a two-echelon distribution system. Sternbeck and Kuhn (2014) determine store delivery patterns in grocery retailing. Sternbeck (2015) develops a model to define the ship-pack optimum quantity focused on the store and Broekmeulen et al. (2017) provide a model for selecting the optimal product unpacking location in a retail supply chain. A more detailed description of these works can be found at Broekmeulen et al. (2017).

As one can see, choosing the "ideal" handling unit to balance the work and the inventory between the distribution centre and the retail store is a complex exercise demanding accurate operational cost models that need to reflect the "best scenario" for supply chain stakeholders. Empirical research is essential to drive the evolution of this research topic and to help to establish a coherent unifying reference. The experimental observations are fundamental to understand the real modern complex systems, and they can be used to test hypotheses, to develop standards, and to create theories.

\section{Studying the Handling Unit in a Portuguese Food Retail Distribution Centre}

The case study reported in this work took place in a Portuguese (multinational) food retail company that is a national market leader in this business area. The company has positions along the entire retail supply chain including production centres, distribution centres, small warehouses, and stores. The company sells directly to the end customer through a wide range of physical stores (e.g., hypermarkets, convenience supermarkets, cafeterias, and restaurants) and online store. It has two 
large distribution centres/logistics platforms, supplying the North region, the South region of the country, and the insular region, and has other smaller warehouses for distinct business segments. The system-in-analysis includes one of the major distribution centres and its client stores (hypermarkets and convenience supermarkets) and the focus is the analysis of the conversion of the handling unit.

\subsection{Handling Unit of the Company along the Supply Chain}

The distribution centre in analysis has two distinct warehouse environments: PBL (picking by line), and PBS (picking by store). The PBS environment has a storage function (working with 5200 Stock Keeping Units, SKUs of high demand) and only receives single product pallets while the PBL environment has a cross-docking function, shipping in less than 24 hours, and may receive multiproduct pallets. The products allocated to PBL (rounding 15000 SKUs) are characterized by high service level rates of suppliers, products with lower demand, high unitary cost, and short shelf life.

In terms of layout:

- PBS environment: space is divided into five zones corresponding to different product categories or business units; 34 corridors with ground-level fixed picking locations for each SKU and storage locations, above the floor, for reservation (if necessary); the picking operation flows according to the store order.

- PBL environment: space has floor fixed positions for each store and the slave pallet (support base for a palletized load with Euro-pallet dimensions) receives the necessary SKUs to fulfil the order of the store; there are four docks for receiving and dispatching located on the same side of the warehouse.

The Handling Unit (HU) at these environments is different: PBS receives, from the suppliers, single product half-pallets or pallets while PBL receives multiproduct pallets (may not be full). The halfpallet is a slave pallet with two packaged units (each one occupies the space of half-pallet). Figure 1 synthesizes the variations of the HU along the company's supply chain.

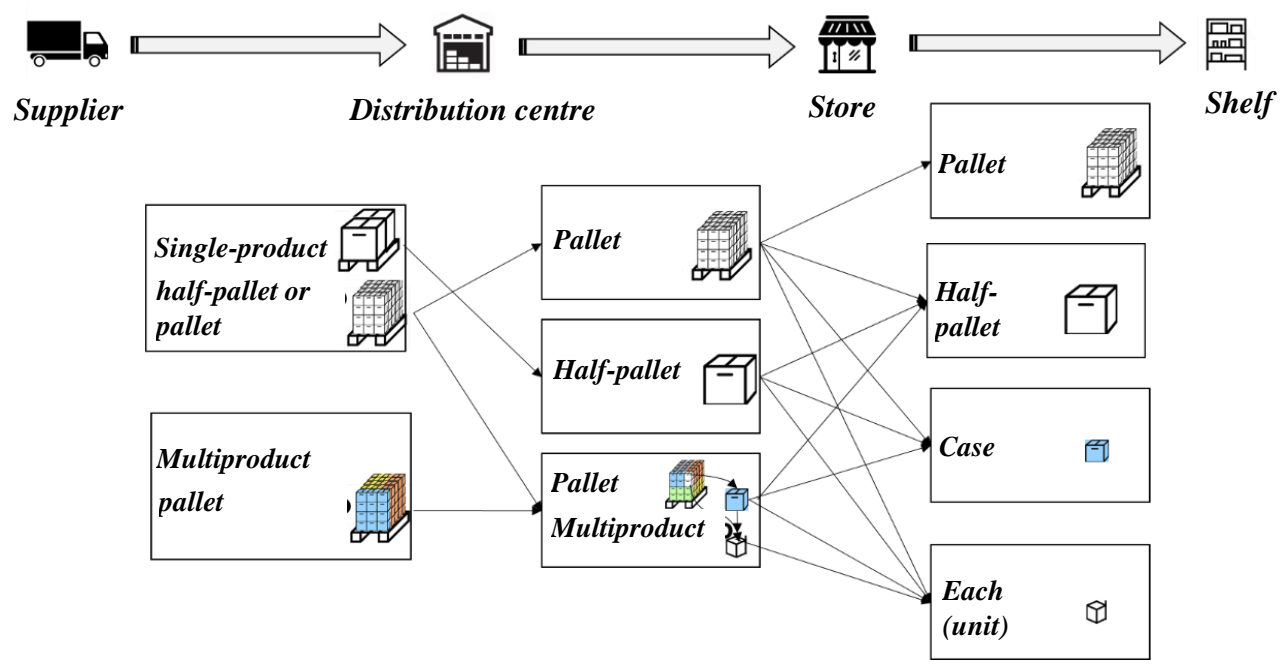

Figure 1. Variations of the handling unit along the company's supply chain 
The ship-pack sent to the stores can assume one of the following configurations: single-product pallet, single-product half-pallet, or multiproduct pallet (resulting from picking operations at both warehouse environments). The multiproduct pallet is made of cases and within each case is a pack of units (eaches). At the store, the consumer has available, at the shelf, different options (depending on the brand and on the store): pallet, half-pallet, case, or each/unit. Besides this presentation to the consumer, the sales are only made in cases or units.

\subsection{Problem and Objectives of the Study}

After an exhaustive logistics data analysis, it was found that during the year 2016 the ship-packs to stores in half-pallet represented about $1 \%$ of the total transfers of the company (24\% are made in full pallet and $75 \%$ in cases inserted into multiproduct pallets). This percentage corresponds to 143 SKUs (98 SKUS from PBS and 45 SKUs from PBL) which is, less than $0,1 \%$ of the total number of SKUs in both warehouses. The company believes that the half-pallet, as handling unit, can provide economic gains as well as productivity improvements in the two-tier distribution system involved in the company's supply chain. Moreover, in the PBS environment, the space allocated to half-pallets has been increasing.

At the distribution centre, the utilization of half pallets can improve the picking operations' ergonomic conditions and reduce the related human errors. At the store, the presentation of halfpallet to the consumer, on the shelf, may influence positively the volume of sales as well as the frequency of shelf replenishment (reducing the frequency), reducing the probability of rupture thus increasing the service level and the consumer's satisfaction. As expected, the company needs to pay attention to a possible increase in inventory at the distribution centre and at the store.

In this context, the company wants to increase the half-pallet (as handling unit) quota of transfers between the distribution centre and the stores but needs to support this decision quantitatively and evaluate the potential economic gains. So, the challenge was to answer the following questions: What are the main activities and flows of the two-tier system? What are the scenarios to compare? What are the cost components to consider in the study? What are the SKUs to elect? What is the economic gain of using the half-pallet as a handling unit?

\subsection{Cost Model}

The definition of a simple cost model to use in the study was preceded by a comprehensive analysis of the engaged supply chain levels (activities and flows), the scenarios to consider, the cost components to include, and the SKUs to elect for half pallet handling.

\subsubsection{Supply Chain Mapping: Distribution Centre (PBS and PBL Warehouses) and Stores}

The system-in analysis comprehends a two-echelon or two-tier distribution system consisting of a distribution centre, with two warehouse environments (PBS and PBL), and the stores supplied by this centre.

The main activities and flows of the PBS warehouse involve the reception of materials (singleproduct half-pallets or pallets), their storage, and the expedition to the stores. The truck is unloaded and the product waits at the reception area to be stored (sometimes, the half-pallets need to be transferred to a slave pallet). The material is transported to (1) ground level fixed picking locations, for each SKU or, (2) reservation storage locations, above the floor (for later replenishment of picking locations, on the ground). As already mentioned, at PBS, the picking operation flows 
according to the store order so, the picking strategy is zone picking: the pickers are grouped into zones/sections corresponding to the product category (there are five zones: drinks, grocery, hygiene/beauty, and household cleaning, and pets care) and each picker is responsible to prepare one or two pallets for a given store. Since the pallet to the store can include several product categories (multiproduct pallet), the order for the store may be prepared by several pickers. If the store order represents more than $70 \%$ of a pallet of the same product, the handling unit is considered a pallet and there is no need for picking operation (the pallet is retrieved from the reservation location and is directly placed on the marshalling area of the store, for the expedition). In the case of half-pallets, the wrapping film needs to be removed before picking.

In the PBL warehouse, the key operations involve reception of products (multiproduct pallets), picking to fulfil the order of the stores and, dispatching (in "cross-docking" warehouse there is no storage activity). The four docks for receiving and dispatching are located on the same side of the warehouse. Space has floor fixed positions for each store and the slave pallet receives the necessary SKUs to fulfil the order of the store. Like in the PBS environment, the pickers are grouped into zones/sections corresponding to product categories (drinks, grocery, hygiene/beauty and household cleaning, bakery, and dairy products). When the pallet to the store is complete, the picker brings a new slave pallet to the store position. The finished pallet is then transported to a zone of delivery marshalling waiting to be sent to the store.

In the stores, the product sent by the distribution centre is received and unloaded into a buffer area to be classified by the product category. The product can be replenished during the regular runtime of the store (in case of stock rupture) or can be replenished after store closure (to fulfil the shelf). Regarding the handling unit, there are three possible situations: (1) direct replenishment: the product received in pallet or half-pallet is directly moved to the shelf replacing the pallet currently in use (which is moved to the backroom space), (2) replenishment in cases: the cases in the shelf are removed, the received ones are opened and placed in the shelf and the "old" ones are placed again in the shelf ensuring the FIFO rule, and (3) replenishment in units: functions like the replenishment in cases but the case needs to be open to put the units, individually, in the shelf. At the backroom space, the operator stores the products that did not fit on the shelf, waiting for new replenishment, and dispose of the cardboard wastes.

\subsubsection{Scenarios}

To define, clearly, the scope of the study there were settled three scenarios of analysis to compare. These scenarios are illustrated in Figure 2.

The three scenarios considered can be defined as:

(1) Current scenario: this setting corresponds to the existing handling mode of the SKUs that were selected for half-pallet handling, in both warehouse environments (single-product full pallets are outside the scope of the analysis); the product can be replenished in the store's shelves as half-pallet, case or unit.

(2) Optimistic scenario: this setting refers to the conversion of the handling unit for half-pallet (in the distribution centre and expedition) in the selected SKUs according to the average weekly demand of stores; the product is handled, at the DC, as half-pallet and is replenished into the shelf of the store as half-pallet (direct replenishment).

(3) Conservative scenario: this setting is a combination of the two previous scenarios that is, there is a conversion of the handling unit, in the distribution centre and expedition, for half-pallet but the replenishment of the shelves in the stores is made in cases or units. 
International Journal of Mathematical, Engineering and Management Sciences

Vol. 5, No. 5, 835-850, 2020

https://doi.org/10.33889/IJMEMS.2020.5.5.065

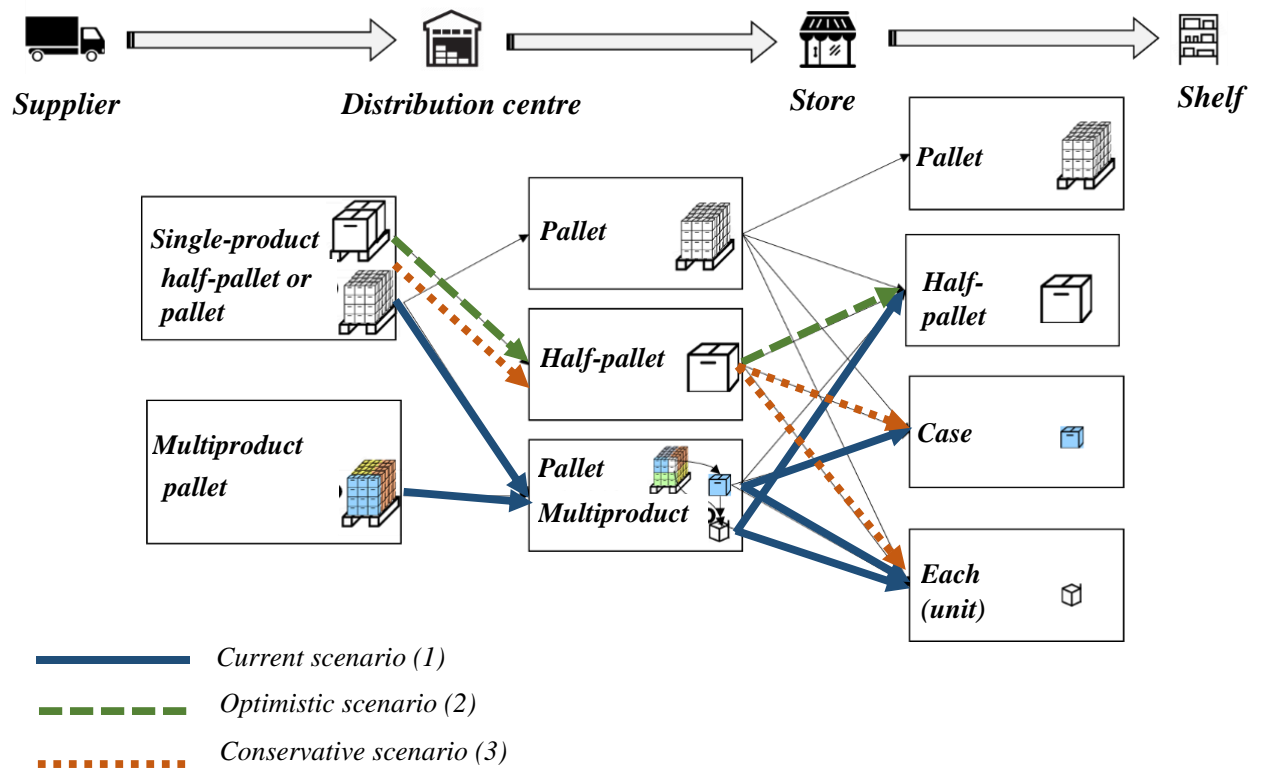

Figure 2. Scenarios considered in the study of the handling unit

\subsubsection{Cost Components}

The cost components to include in the model were chosen based on the potential impact of changing the handling unit along the supply chain so, it was considered several cost elements, for the distribution centre and for the stores, that can be grouped into two main categories: inventory costs and handling costs. Figure 3 illustrates these costs.

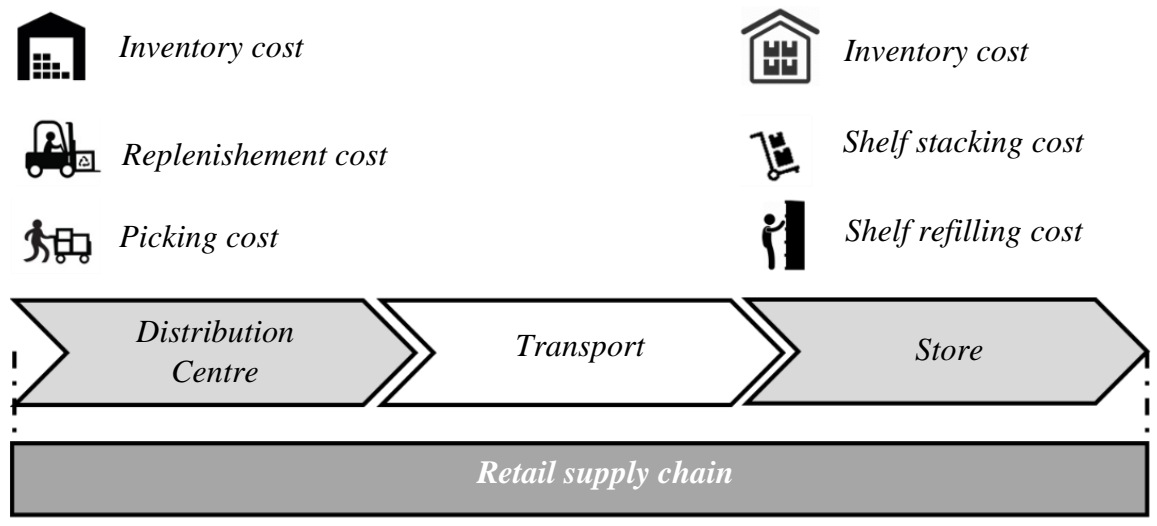

Figure 3. Cost components considered in the study

Regarding the distribution centre, and as Wen (2010) states, the handling unit considerably influences the replenishment cost and the picking cost. The handling unit can also influence the 
International Journal of Mathematical, Engineering and Management Sciences

Vol. 5, No. 5, 835-850, 2020

https://doi.org/10.33889/IJMEMS.2020.5.5.065

inventory cost at the distribution centre due to a potential impact on the safety stock. The modification of the HU has an impact on the replenishment lead time of the store that will affect the stock levels in the upper supply chain echelon.

Regarding the store side, the modification of the handling unit will probably affect the shelf space, and consequently, shelf stacking and shelf refilling operations will have an impact on the related handling costs. The inventory levels will probably change so, it is important to consider the inventory costs at the store.

After a comprehensive analysis of the system at hand, these costs were chosen due to their potential impact on the supply chain activity of the company and based on their representativeness on the daily operations. The other logistic costs were not contemplated in the model because they were not considered so relevant. Also, it was intended to keep a simple model focused on the critical cost elements of the system-in-analysis.

\subsubsection{SKUs for Half-Pallet Handling}

The election of the SKUs to include in the study was based on an ABC analysis to categorize the items with a larger volume of cases shipped during the year of 2016. Considering a population of about 20792 SKUs, it was verified that $85 \%$ of the quantity shipped in cases corresponds to $22 \%$ of SKUs that is, 4636 SKUs. This number was considered too high for the study so, the working team decided to include, in a first phase, only $20 \%$ of the quantity shipped corresponding to 137 SKUs.

After this analysis, the work proceeded with a study of the demand patterns according to the model of Syntetos et al. (2005) considering two independent variables: (i) monthly order size variability and, (ii) the interval between deliveries. Considering the real context, it was pertinent to consider a low monthly variability as well as a low interval between shipments characterizing a demand pattern usually known as continuous. This scrutiny allowed the definition of the final set to consider in the study: 105 SKUs.

\subsubsection{Model Formulation}

The cost model defined for the study includes several cost components distributed by three main categories: handling costs at the distribution centre, handling costs at the store, and inventory costs at both locations. The central idea is to compute a total year-based cost, for each SKU, considering the two-tier distribution system, to evaluate the best operating scenario that is, the scenario with the lower cost when the handling unit is the half pallet. The objective function is depicted in equation (1):

$$
\text { Total cost }_{S K U}=C^{\text {inv } . D C}+\sum_{j \in J} C_{j}^{\text {inv } . S T}+S \times C^{\text {rep. } . D C}+S\left(\sum_{j \in J} C_{j}^{\text {pick. } . D C}+C_{j}^{\text {stack } . S T}+C_{j}^{\text {refil } . S T}\right)
$$

where:

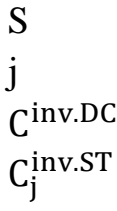

$\mathrm{S}$

$C^{\text {inv.DC }}$

$C_{j}^{\text {inv.ST }}$ number of weeks in a year

number of stores supplied with picking (of cases)

inventory cost at the distribution centre

inventory cost at the store 
International Journal of Mathematical, Engineering and Management Sciences

Vol. 5, No. 5, 835-850, 2020

https://doi.org/10.33889/IJMEMS.2020.5.5.065

$$
\begin{array}{ll}
C^{\text {rep.DC }} & \text { replenishment cost at the distribution centre } \\
\mathrm{C}_{\mathrm{j}}^{\text {pick.DC }} & \text { picking cost at the distribution centre } \\
\mathrm{C}_{\mathrm{j}}^{\text {stack.ST }} & \text { shelf stacking cost at the store } \\
\mathrm{C}_{\mathrm{j}}^{\text {refil.ST }} & \text { shelf refilling cost at the store }
\end{array}
$$

The cost model assumes that the demand has a continuous constant pattern; the transportation costs are independent of the handling unit and are fixed; there are no stock ruptures; the shelf stacking and shelf refilling costs are independent of the location on the shelf and the stores do not have capacity restrictions.

\section{Discussion of Results}

The cost model was applied to the system-in-analysis (105 SKUs) and, as illustrated in figure 4, 26 SKUs were allocated to Scenario 1 (current), 48 SKUs to Scenario 2 (optimistic) and 31 SKUs to Scenario 3 (conservative). These results suggest that for 26 SKUs it is preferable to keep the current handling unit while for the other 79 SKUs it is desirable to convert the handling unit for half-pallet. Within this set, 48 SKUs will be sent to the stores in half-pallet and will also be replenished into the shelves as half-pallet. The others 31 SKUs will be sent to the stores in half-pallet but replenished into the shelves in cases or units.

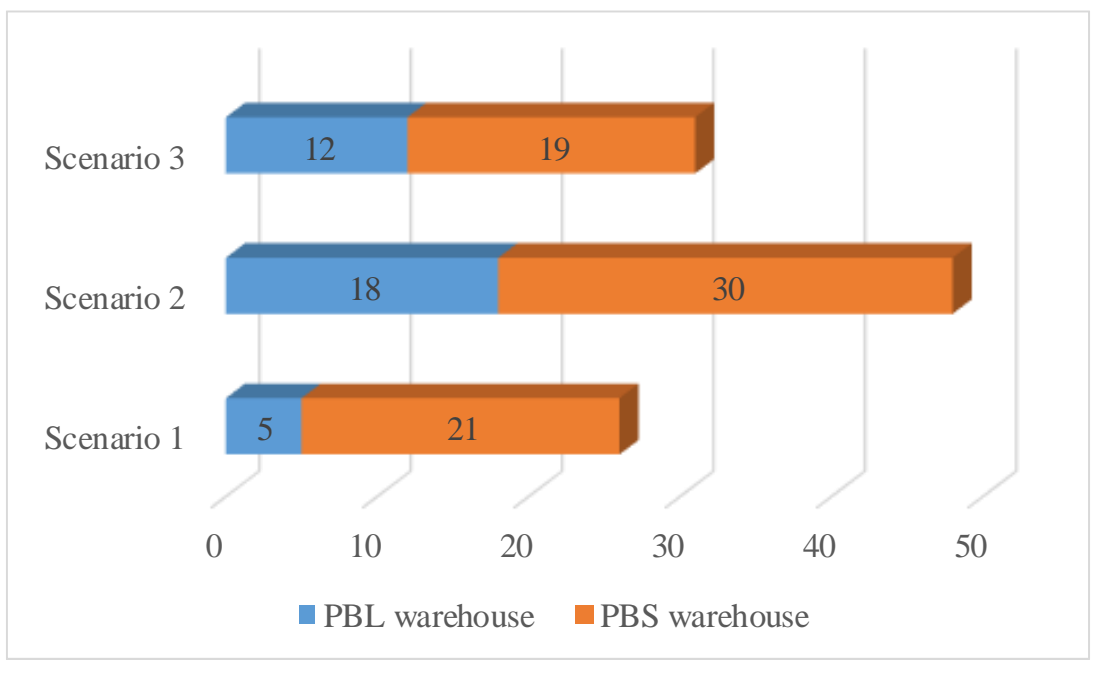

Figure 4. General results of the cost model

These general results were deeply examined, and it was found that for both warehouse environments (figure 5):

- in the current scenario (scenario 1), the total cost is highly influenced by the handling cost at the distribution centre which is, in turn, strongly roused by the picking activity (and inherent cost);

- in the optimistic scenario (scenario 2), the cost component more significant is the handling cost at the store having the shelf stacking cost the higher impact;

- in the conservative scenario (scenario 3), the weightier cost components are the inventory cost in the store and the handling cost at the store (mostly due to shelf refilling cost). 
International Journal of Mathematical, Engineering and Management Sciences

Vol. 5, No. 5, 835-850, 2020

https://doi.org/10.33889/IJMEMS.2020.5.5.065

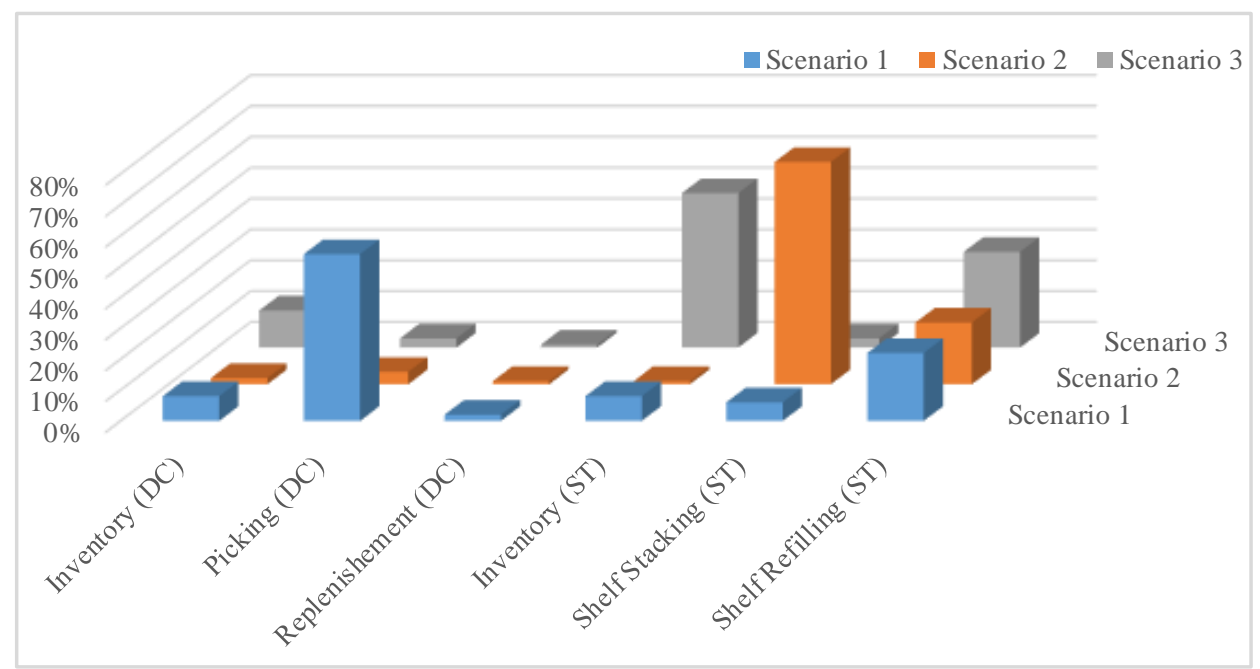

Figure 5. Impact of cost components on the total cost across the three scenarios

The SKUs allocated to the current scenario shows that it is advisable, for these products, to keep the existing handling mode: the inventory costs (at the distribution centre and the stores) rise significantly in scenarios 2 and 3 because the quantity sent to the stores increases with the halfpallet handling mode; regarding the handling cost in the stores, in general, using the half-pallet the space in the shelf decreases so, the shelf refilling cost increases; the half-pallet handling mode impels more replenishment activities in the distribution centre and consequently, the conversion is not an interesting option.

Analysing the SKUs allocated to the optimistic scenario, it is possible to observe a considerable positive impact in the store handling costs because the shelf space dedicated to each SKU is bigger and thus it is not necessary to refill the shelf so often. For these products, the conversion to the halfpallet brings interesting economic gains when looking to picking activities at the distribution centre.

The SKUs allocated to the conservative scenario evidence that the half-pallet handling mode at the distribution centre has economic gains in terms of picking costs that compensate the shelf refilling costs at the store.

This analysis led to the design of a pilot field test, with a smaller sample of SKUs, to validate the cost model and support the major decision of conversion of the handling unit. For this test the company selected, based on an ancillary $\mathrm{ABC}$ analysis, 18 SKUs previously allocated to scenarios 2 and 3. The resulting field data allowed us to validate the cost model. When projecting the results for one year, it was possible to estimate savings rounding 5\% of total costs. Despite the increase in inventory costs, the great benefit, as can be observed in figure 6 , stems from the reduction in handling costs (both at the distribution centre and the stores) that greatly restrain the increase in the inventory component. 
International Journal of Mathematical, Engineering and Management Sciences

Vol. 5, No. 5, 835-850, 2020

https://doi.org/10.33889/IJMEMS.2020.5.5.065

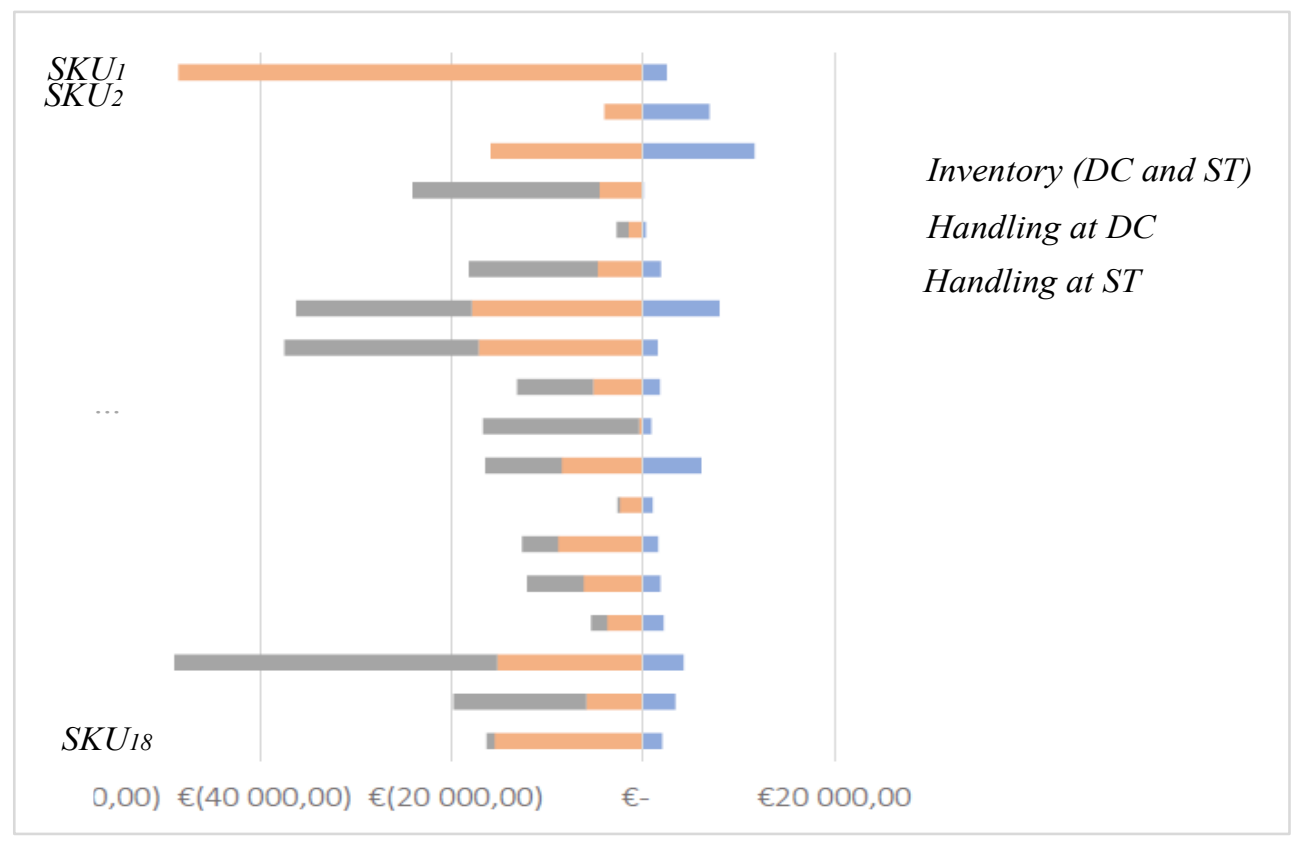

Figure 6. Balance of gains in the pilot field test

This study and the pilot test were critical to aid the decision-making process and the inherent model was essential to quantify the potential benefits of the conversion of the handling unit in the two-tier distribution system. In general terms, the introduction of the half-pallet results in more quantity of products sent to the stores reducing the frequency of deliveries of the distribution centre. When the half-pallet is directly used on the shelf it is observed a saving in the shelf refilling costs. As already evidenced by other authors (Kuhn and Sternbeck, 2013; Sukhotu and Iamratanakul, 2013; Sternbeck, 2015), the study confirms that the handling costs at the store (shelf stacking and shelf refilling) are a large part of total overall costs with a quota of approximately $80 \%$.

\section{Conclusion}

The study reported in this paper was devoted to evaluating the potential benefits of converting the handling unit (or ship-pack) in a two-tier distribution system of a Portuguese food retail company. As mentioned by several authors, the handling unit has a considerable influence on logistics efficiency and costs of the supply chain so, it is very important to evaluate those performance indicators and quantify them.

The cost model developed was designed for the reality-at-hands aiming to evidence the most important logistic components of the two-tier distribution system of the company. The results of the study highlight the potential gains of using the half pallet handling unit revealing the critical need to focus attention on the store/shelf management because the handling costs at the store are considered significant when compared to the other costs components.

The authors believe that empirical research is needed to understand and model adequately modern complex systems such as food retail supply chains. The field-based studies are essential to driving the evolution of knowledge. 
International Journal of Mathematical, Engineering and Management Sciences

Vol. 5, No. 5, 835-850, 2020

https://doi.org/10.33889/IJMEMS.2020.5.5.065

The company is interested in pursuing this study and some future works are already planned: to include the rupture component in the model (the cost model may accommodate more cost components, to allow a more detailed and exhaustive analysis), to complement the analysis with a comprehensive supply chain simulation study to evaluate the dynamics of the system, and to assess the impact of introducing the quarter-pallet as handling unit for some SKUs.

\section{Conflict of Interest}

The authors confirm that there is no conflict of interest to declare for this publication.

\section{Acknowledgments}

The authors would like to thank the food retail company involved in this work for allowing us free access to all the information used, for their contribution to the project and for their willingness to allow us to share this experience.

\section{References}

Albán, H.M.G., Cardona, O.C.S., Argueta, C.M., \& Sarmiento, A.T. (2015). A cost-efficient method to optimize package size in emerging markets. European Journal of Operational Research, 241(3), 917926.

Avlijas, G., Simicevic, A., Avlijas, R., \& Prodanovic, M. (2015). Measuring the impact of stock-keeping unit attributes on retail stock-out performance. Operations Management Research, 8(3-4), 131-141.

Bourlakis, M.A., \& Bourlakis, C.A. (2001). Deliberate and emergent logistics strategies in food retailing: a case study of the Greek multiple food retail sector. Supply Chain Management: An International Journal, 6(4), 189-200.

Broekmeulen, R.A., Sternbeckb, M.G., van Donselaara, K.H., \& Kuhn, H. (2017). Decision support for selecting the optimal product unpacking location in a retail supply chain. European Journal of Operational Research, 259(1), 84-99.

Chiu, Y.-S., Chen, Y.-R., Wu, H.-Y., \& Chou, C.-L. (2020). Determining the economic manufacturing lot size with expedited fabrication rate and product quality assurance. International Journal of Mathematical, Engineering and Management Sciences, 5(2), 193-207.

Corsten, D., \& Gruen, T. (2003). Desperately seeking shelf availability: an examination of the extent, the causes, and the efforts to address retail out-of-stocks. International Journal of Retail \& Distribution Management, 31(12), 605-617.

Das, K. (2019). Integrating lean, green, and resilience criteria in a sustainable food supply chain planning model. International Journal of Mathematical, Engineering and Management Sciences, 4(2), 259-275.

de Koster, R., Le-Duc, T., \& Roodbergen, K.J. (2007). Design and control of warehouse order picking: a literature review. European Journal of Operational Research, 182(2), 481-501.

Eroglu, C., Williams, B.D., \& Waller, M.A. (2011). Consumer-driven retail operations: the moderating effects of consumer demand and case pack quantity. International Journal of Physical Distribution \& Logistics Management, 41(5), 420-434.

Fernie, J., Sparks, L., \& McKinnon, A.C. (2010). Retail logistics in the UK: past, present and future. International Journal of Retail \& Distribution Management, 38(11/12), 894-914. 
International Journal of Mathematical, Engineering and Management Sciences

Vol. 5, No. 5, 835-850, 2020

https://doi.org/10.33889/IJMEMS.2020.5.5.065

Forslund, H. (2015). Performance management process integration in retail supply chains. International Journal of Retail \& Distribution Management, 43(7), 652-670.

Gu, J., Goetschalckx, M., \& McGinnis, L.F. (2007). Research on warehouse operation: a comprehensive review. European Journal of Operational Research, 177(1), 1-21.

Gunasekaran, A., \& Ngai, E.W. (2005). Build-to-order supply chain management: a literature review and framework for development. Journal of Operations Management, 23(5), 423-451.

Holweg, C., Teller, C., \& Kotzab, H. (2016). Unsaleable grocery products, their residual value and in store logistics. International Journal of Physical Distribution \& Logistics Management, 46(6/7), 634-658.

Hübner, A., \& Schaal, K. (2017). An integrated assortment and shelf-space optimization model with demand substitution and space-elasticity effects. European Journal of Operational Research, 261(1), 302-316.

Kuhn, H., \& Sternbeck, M.G. (2013) Integrative retail logistics: an exploratory study. Operations Management Research, 6, 2-18. https://doi.org/10.1007/s12063-012-0075-9.

Mena, C., \& Bourlakis, M. (2016). Retail logistics special issue. International Journal of Physical Distribution \& Logistics Management, 46(6/7). https://doi.org/10.1108/IJPDLM-03-2016-0098.

Molina, A., Martín, V.J., Santos, J., \& Aranda, E. (2009). Consumer service and loyalty in Spanish grocery store retailing: an empirical study. International Journal of Consumer Studies, 33(4), 477-485.

Nasir, M.H.A., Genovese, A., Acquaye, A.A., Koh, S.C.L., \& Yamoah, F. (2017). Comparing linear and circular supply chains: A case study from the construction industry. International Journal of Production Economics, 183(Part B), 443-457.

Perez-Franco, R., Phadnis, S., Caplice, C., \& Sheffi, Y. (2016). Rethinking supply chain strategy as a conceptual system. International Journal of Production Economics, 182, 384-396.

Prajogo, D., Oke, A., \& Olhager, J. (2016). Supply chain processes: linking supply logistics integration, supply performance, lean processes and competitive performance. International Journal of Operations \& Production Management, 36(2), 220-238.

Schramm-Klein, H., \& Morschett, D. (2006). The Relationship between marketing performance, logistics performance and company performance for retail companies. The International Review of Retail, Distribution and Consumer Research, 16(2), 277-296.

Sternbeck, M.G. (2015). A store-oriented approach to determine order packaging quantities in grocery retailing. Journal of Business Economics, 85(5), 569-596.

Sternbeck, M.G., \& Kuhn, H. (2014). An integrative approach to determine store delivery patterns in grocery retailing. Transportation Research Part E, 70, 205-224.

Sukhotu, V., \& Iamratanakul, S. (2013, December). An EOQ model with consideration of second-trip instore replenishment. In 2013 IEEE International Conference on Industrial Engineering and Engineering Management (pp. 231-235). IEEE. Bangkok, Thailand.

Syntetos, A.A., Boylan, J.E., \& Croston, J.D. (2005). On the categorization of demand patterns. Journal of the Operational Research Society, 56(5), 495-503.

Tarafdar, M., \& Qrunfleh, S. (2017). Agile supply chain strategy and supply chain performance: complementary roles of supply chain practices and information systems capability for agility. International Journal of Production Research, 55(4), 925-938.

Voss, C., Tsikriktsis, N., \& Frohlich, M. (2002). Case research in operations management. International Journal of Operations \& Production Management, 22(2), 195-219. 
International Journal of Mathematical, Engineering and Management Sciences

Vol. 5, No. 5, 835-850, 2020

https://doi.org/10.33889/IJMEMS.2020.5.5.065

Wen, N. (2010). Optimization of ship-pack in a two-echelon distribution system. Master Thesis in Computation for Design and Optimization, Massachusetts Institute of Technology, USA.

Wen, N., Graves, S.C., \& Ren, Z.J. (2012). Ship-pack optimization in a two-echelon distribution system. European Journal of Operational Research, 220(3), 777-785. 